\title{
ISOLATED IVC THROMBUS: A RARE COMPLICATION OF PANCREATITIS
}

Senthil Kumaran Marimuthu' ${ }^{1}$, Manoj P2 ${ }^{2}$ Ram Badari Narayan ${ }^{3}$

\section{HOW TO CITE THIS ARTICLE:}

Senthil Kumaran Marimuthu, Manoj P, Ram Badari Narayan. "Isolated IVC Thrombus: A Rare Complication of Pancreatitis". Journal of Evolution of Medical and Dental Sciences 2014; Vol. 3, Issue 23, June 09;

Page: 6513-6515, DOI: $10.14260 /$ jemds/2014/2774

ABSTRACT: Venous thrombosis and hypercoagulable state has been described in patients with acute and chronic pancreatitis. Though this is commonly observed in splanchnic vessels, thrombosis of IVC is not frequently encountered. ${ }^{1}$

KEYWORDS: Pancreatitis, pseudocyst, IV thrombosis.

CASE REPORT: A 32years old male with alcoholic pancreatitis with previous episode of acute pancreatitis three months ago, presented to us with acute abdomen. Examination of the abdomen revealed a $8 \times 15 \mathrm{cms}$ mass in left upper quadrant extending into right upper quadrant, non-mobile, not moving with respiration, mildly tender and dull on percussion. Investigations revealed mildly elevated serum and urinary amylase.

CT abdomen revealed pseudocyst pancreas measuring $8 \times 16 \mathrm{cms}$ pushing stomach anterolaterally, extending anteriorly up to anterior abdominal wall with features consistent of chronic pancreatitis. An unusual finding was large intraluminal thrombus within IVC extending up to confluence of iliac veins. The patient did not have lower limb edema or abdominal collaterals despite involvement of intra-abdominal IVC.

DISCUSSION: Vascular complications in pancreatitis are well documented. Acute pancreatitis has also found to generate thrombosis of the inferior vena cava. ${ }^{2,3}$ The pathogenesis of IVC thrombosis in pancreatitis is not well understood, but the contributing factors could be-inflammation, edema and cellular infiltration adjacent to IVC, hypercoagulable state, mass effect and compression due to pseudocyst and bulky pancreas, intimal injury caused by pancreas. ${ }^{4}$

Although inferior vena cava thrombosis in the setting of pancreatitis is rare, this clinical entity may account for an unexplained deterioration in the status of a patient with pancreatitis. And this can be effectively treated with anticoagulation and hence mortality related to complication such as pulmonary embolism can be prevented. ${ }^{5}$

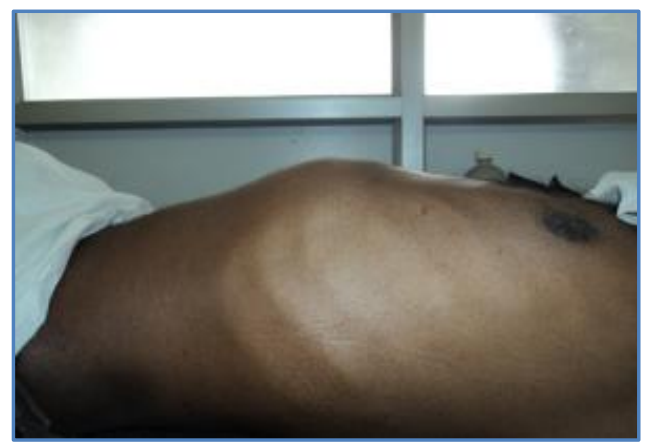

Fig. 1: Side view of abdomen of patient showing distension due to pseudocyst pancreas 


\section{CASE REPORT}

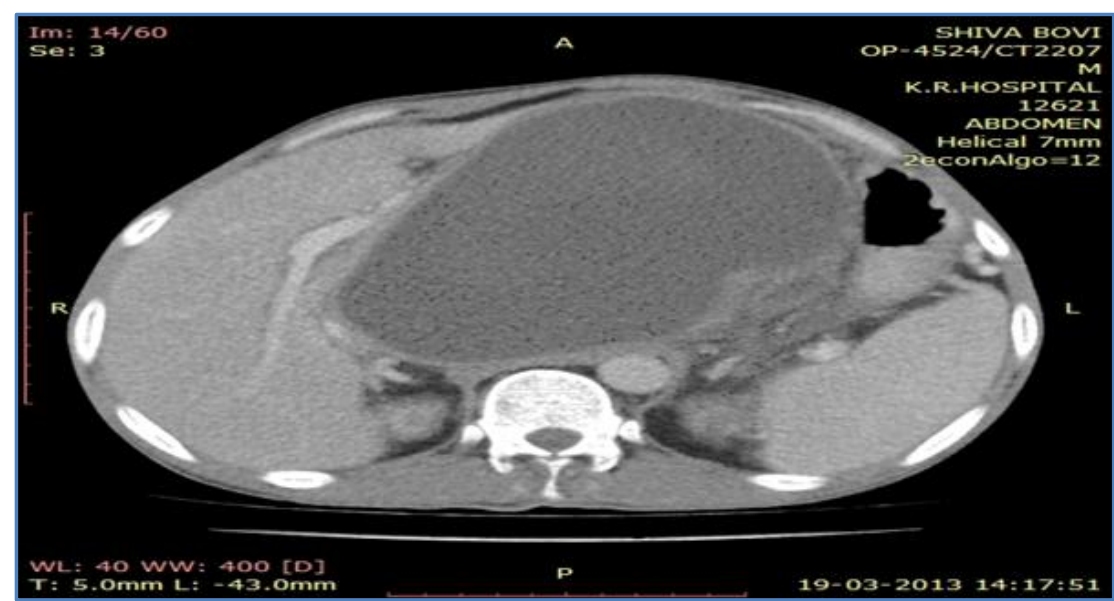

Fig 2: Contrast CT of abdomen showing pseudocyst pancreas pushing stomach anterolaterally and extending up to anterior abdominal wall

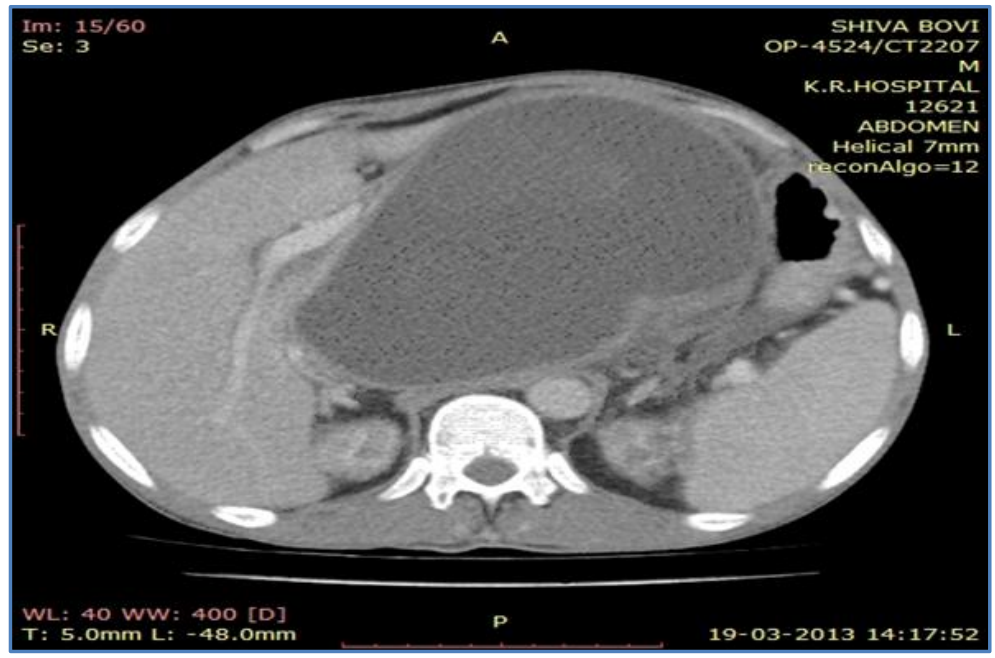

Fig. 3: Contrast CT of abdomen showing thrombus in IVC

\section{REFERENCES:}

1. Nordback I, Sisto 'T. Peripancreatic vasular occlusions as a complication of pancreatitis. Int Surg 1989; 74: 36-9.

2. Nicholas de Prado I, Corral de la MA, Nicholas de Prado JM, Gallardo Sanchez, F, Medranda MA. Vascular complications of pancreatitis. Rev Clin Esp 2005; 205; 326-32.

3. Besselink MG. Splanchnic vein thrombosis complicating severe acute pancreatitis. HPB (Oxford) 2011; 13: 860-4.

4. Stringer MD, Michell M, McIrvine AJ. Inferior vena caval thrombosis complicating acute pancreatitis. Case report. Acta Chir Scand 1988; 154: 161-3.

5. Alvi AR, Bibi S, UR Rehman. Acute mesenteric, portal and inferior vena cava thrombosis; optimal outcome achieved with anticoagulation. J Pak Med Assoc 2010; 60: 397-9. 


\section{CASE REPORT}

\section{AUTHORS:}

1. Senthil Kumaran Marimuthu

2. Manoj P.

3. Ram Badari Narayan.

\section{PARTICULARS OF CONTRIBUTORS:}

1. Senior Resident, Department of General Surgery, Mysore Medical College, Mysore.

2. Senior Resident, Department of General Surgery, Mysore Medical College, Mysore.

3. Senior Resident, Department of General Surgery, Mysore Medical College, Mysore.

\section{NAME ADDRESS EMAIL ID OF THE} CORRESPONDING AUTHOR:

Dr. Senthil Kumaran M, Department of General Surgery, Mysore Medical College,

Mysore.

Email: sivaji.deboss@gmail.com

Date of Submission: 22/05/2014.

Date of Peer Review: 23/05/2014.

Date of Acceptance: 31/05/2014.

Date of Publishing: 09/06/2014. 